\title{
Dieting, mindfulness and mindful eating: exploring whether or not diets reinforce mindfulness and mindful eating practices
}

\section{BACKGROUND}

Research into dieting and mindfulness has primarily focused upon how mindfulness and mindful eating affect dieting. However, the effect is bi-directional, with the process of dieting also impacting on mind-set and eating. We therefore aimed to investigate how people on different diets experience mindfulness and mindful eating. The present research aimed to explore whether or not specific weight loss diets are likely to prompt more of the elements described in mindfulness and mindful eating theory.

\section{PARTICIPANTS AND PROCEDURE}

A community sample $(N=312)$ who were dieting at the time of recruitment were asked to fill in mindfulness and mindful eating measures, where commercial weight loss programmes (CWLP), low carbohydrate (LC), and intermittent fasting (IF) were used as dieting methods, as well as general healthy eating $(\mathrm{GHE})$. Analyses of variance were conducted with the intention of comparing those groups in mindfulness and mindful eating, as well as their corresponding sub-constructs. The questionnaires and demographic information were provided through an online

\begin{abstract}
database, as well as other information relating to the diet,
\end{abstract} duration and history of dieting.

\section{RESULTS}

The results showed intermittent fasting dieters to score higher across mindfulness and mindful eating scores, although the differences from the rest of the groups were not significant. Investigating mindful eating further through the subscales revealed that CWLP scores were significantly higher in 'routine' when compared to GHE. Trait mindfulness subscales displayed no significant differences, except 'describe', which was higher in CWLP over LC dieting.

\section{CONCLUSIONS}

Specific emphasis is given to future directions, and the potential to identify diets that are theoretically and practically consistent with the theory and practices of mindfulness and mindful eating.

KEY WORDS

mindfulness; mindful eating; dieting; obesity; intermittent fasting

ORGANIZATION - Birmingham City University, Birmingham, United Kingdom

AUthors' CONTRibutions - A: Study design - B: Data collection - C: Statistical analysis - D: Data interpretation .

E: Manuscript preparation · F: Literature search · G: Funds collection

Corresponding Author - Michail Mantzios, Ph.D., Birmingham City University, The Curzon Building Room C307,

B4 7BD Birmingham, United Kingdom, e-mail: michael.mantzios@bcu.ac.uk

to CITE THIS ARTICle - Manku, R. S., Egan, H., Keyte, R., Hussain, M., \& Mantzios, M. (2020). Dieting, mindfulness and mindful eating: exploring whether diets reinforce mindfulness and mindful eating practices. Health Psychology Report, 8(1), 59-67. https://doi.org/10.5114/hpr.2019.88057

RECEIVED 09.07.2019 • REVIEWED 07.08.2019 • ACCEPTED 15.08.2019 • PUBLISHED 18.09.2019 


\section{BACKGROUND}

A growing concern in health research is the rising figures of obesity (World Health Organisation, 2000). The health problems associated with obesity are also increasingly problematic (such as diabetes and cardiovascular disease), and have led many researchers to attempt to combine dieting with mindfulness for greater effectiveness. Dieting used to aid weight loss, is normative and shows that even people who do not need to diet are dieting (Foxcroft, 2012; Germov \& Williams, 1996). The range of commercial advice available extends from trademark dietary plans and food to diets that do not have any empirical support. This plethora of diets alter the way people engage with their food and the way that they eat. Notably, the lack of effective behavioural interventions means that there is a constant reuptake of the diet that previously worked for a period of time, and a continued cycle of dieting and non-dieting which does little to help address the issue of obesity.

This impasse has further led to research utilising mindfulness training to aid individuals in regulating their weight through a more community health based approach, where everyone can achieve better health outcomes through better eating behaviours (Lillis, Hayes, Bunting, \& Masuda, 2009; Dalen et al., 2010; Mantzios \& Giannou, 2014; Mantzios \& Wilson, 2014a; Mantzios \& Wilson, 2015a). Initial results have been positive, but a number of questions regarding the pairing of mindfulness and dieting remain.

Overall, while the theoretical descriptions of mindfulness promote a non-judgmental attitude, mindful attention of eating and of the food consumed, and responding to internal cues such as hunger and satiety, the enactments of many diets promote opposing messages to dieters, advocating ignoring such cues, and promoting judgmental attitudes towards eating. This research proposes that certain types of diets may reflect more basic characteristics of mindfulness and mindful eating in comparison to other diets and sets out to explore whether some diets are more likely than others to promote increased levels of mindfulness and mindful eating in people who are currently attempting to lose weight.

Mindfulness is a method of purposely paying attention to the present moment without judgment (Kabat-Zinn, 1990), and many researchers and clinicians have proposed that mindful eating (i.e., mindfulness foundations applied to eating) may be a method of regulating eating (e.g., Kristeller \& Wolever, 2010). Mindful eating is defined as the act of responding to physiological cues such as hunger, taste, and fullness, while maintaining non-judgmental attention throughout the duration of eating. Examples include making specific food choices that are aligned to sensory experiences and being aware of internal cues to eat such as hunger and satiety, rather than elements in the envi- ronment that predispose people to eat out of habit or diverted attention (Kristeller \& Wolever, 2010). There are several studies that outline the positive outcomes of mindfulness and mindful eating.

Mindful eating assists in the gradual change of problematic eating patterns that lead to obesity by promoting healthier eating behaviours (Mantzios \& Wilson, 2014b; Mantzios \& Wilson, 2015a; Mantzios \& Giannou, 2014), including a decrease in external and emotional eating (Warren, Smith, \& Ashwell, 2017; O'Reilly, Cook, Spruijt-Metz, \& Black, 2014), an increased intake of fruit and vegetables (Dutt, Keyte, Egan, Hussain, \& Mantzios, 2018; Gilbert \& Waltz, 2010), as well as a reduction in the consumption of high-sugar and energy-dense foods (Mason et al., 2016). Research has found a negative association between mindfulness and mindful eating and fat and sugar consumption (Mantzios, Egan, Hussain, Keyte, \& Bahia, 2018), motivation to eat palatable foods (Mantzios \& Egan, 2018), grazing (Mantzios, Egan, Bahia, Hussain, \& Keyte, 2018), and weight gain (Mantzios, Wilson, Linnell, \& Morris, 2015). Overall, mindfulness, and more significantly, mindful eating, was found to be more effective in improving eating behaviours (see also Mantzios \& Wilson, 2015b). Research has indicated that the improvement seen in mindful eating interventions may be due to enhanced self-regulation around food.

Many researchers have attempted to combine mindfulness and mindful eating principles with dieting to assist people in regulating their weight (Kristeller \& Wolever, 2010; Tapper et al., 2009). A recent study by Hendrickson and Rasmussen (2017) found that participants who took part in mindful eating were able to display more control over their food choices. Dalen et al. (2010) and Lillis et al. (2009) used mindfulness and mindful eating principles to aid overweight individuals and found a significant reduction in weight and psychological distress. Mantzios and Wilson (2014b) developed a mindful diary that followed the principles of mindful eating and showed success in the loss and maintenance of weight, while Hussein, Egan, and Mantzios (2017) showed that diaries enhanced levels of mindfulness and self-compassion and lowered anxiety by simply considering the questions of the diary rather than writing the answers. Overall research has shown that the mindfulness eating diaries were effective in reducing weight and in assisting with psychological wellbeing, in line with most research within the literature. The focus of the research to date has been on whether and how mindfulness may influence dieting, rather than the effect of dieting on mindfulness and mindful eating, especially when considering the fundamental differences that exist between diets.

Dieting is essentially restricting food intake or only having specific foods to lose weight (Brownell \& Rodin, 1994). Mintel (2014) found 55\% of the UK population tries to diet each year, and the three most popular diets that have been identified are explored next 
(NHS, 2017). Firstly, there are commercial weight loss programmes (CWLP) such as Weight Watchers, Slimming World and the Atkins diet. Whilst they all differ in their way of handling customers, the underlying principle and benefit of CWLP is that of group support (NHS, 2016; Stinson, 2001). CWLP have proved to be effective in reducing weight over time (Ahern, Olson, Aston, \& Jebb, 2011; Dixon, Shcherba, \& Kipping, 2012) for example, Heshka et al. (2003) conducted a longitudinal study where they compared CWLP to self-help and found CWLP to be significantly more effective than self-help strategies. However, Tsai and Wadden (2005) conducted a review and concluded that, with the exception of Weight Watchers, the benefits for CWLP are less clear. The Atkins diet uses the dietary concept of ketosis, where the lowering of carbohydrates forces the body to convert stored fat into energy (NHS, 2016), and is the second most popular method of dieting.

Low carbohydrate (LC) diets are enacted by consuming fewer carbohydrates and increasing other nutrients such as protein or fats (Last \& Wilson, 2006). Studies have shown that individuals are more likely to follow an LC diet when compared to other diets with no adverse effects on health (Bravata et al., 2003; Last \& Wilson, 2006). However, this type of diet has had adverse outcomes such as headaches, constipation and increase of fat consumption (Yancy, Olsen, Guyton, Bakst, \& Westman, 2004). Overall, LC diets have been found to increase psychological wellbeing compared to low fat diets (Yancy et al., 2004). However, research has focused on the Atkins diet, rather than self-help commitment to LC dieting. Third, intermittent fasting (IF) is a dietary concept of having a regular eating pattern for the majority of the week, while for a few days a week calorie intake is severely cut to $25 \%$ of normal intake (600 calories for men, 500 calories for women), with 18-24-hour days of fasting (NHS, 2016). Harvie et al. (2011) in a study looking at IF with a female population over six months found it enabled weight loss in addition to reducing biological risk factors such as type II diabetes.

Diets are generally followed by individuals wanting to lose weight, and may be problematic, especially when considered in association with mindfulness. For example, some LC diets are designed only for short-term use, as adverse clinical side effects such as increases in cortisol production and psychological stress have been observed (Tomiyama et al., 2010). Additionally, Wadden, Stunkard, and Smoller (1986) found that over $50 \%$ of participants displayed deterioration in mood while dieting, with other research indicating an association with anxiety and depression (Bruinsma \& Taren, 2000; Peet, 2004; Tanskanen et al., 2001). Furthermore, individuals who are dieting often develop high self-critical perspectives, where failure to meet dietary expectation and not losing weight are often reiterated through high levels of self-deprecation, especially in overweight populations (Schwartz
$\&$ Brownell, 2004). In addition, the use of a points system in diets and counting calories means that the focus is shifting away from the body, eating and food, and is invested in external cues such as how much food is worth in points or calories, leading to ignoring internal cues of satiety and hunger - an element that is also very evident in IF. Overall, there is a great deal of research which suggests that dieting leads some people to negative outcomes in relation to their wellbeing.

By contrast, mindfulness and mindful eating literature have been found to be supportive of mental health and wellbeing (e.g., Gu, Strauss, Bond, \& Cavanagh, 2015). Mindful eating practices suggest that the individual should focus on the present moment, by attending to the colour, texture, smell and taste of the food through touch, sound, sight, smell and taste (Kabat-Zinn, 2005; Albers, 2003). These practices change the nature of relating to internal cues and food, and have been found to increase levels of pleasure (Hong, Lishner, \& Han, 2014). Also, the fundamental principle of mindfulness and mindful eating is the notion of being attentive and aware of the present moment (or meal), with a non-judgmental attitude, the latter aspect being the exact opposite of the way in which most diets function (e.g., you give yourself a hard time if you fail to resist the chocolate). Some research has suggested that healthy eating offers a more flexible approach than dieting, which is more consistent with mindfulness (Alberts, Mulkens, Smeets, \& Thewissen, 2010). Other research has also shown that people were much more comfortable with healthy eating, and the concept of dieting was eschewed (Egan \& Mantzios, 2018). On the other hand, IF may be a form of returning to a level of increased awareness around food, which may represent a more 'natural' way of being. When food is limited, there is a chance of returning our senses to the body and the food, in ways of observing hunger and satiety, appreciating a meal, slowing down to prolong the pleasure, and reinforcing the ability to regulate food intake in ways that treat food as a method of nourishment and wellbeing. In this research, we measured mindfulness and mindful eating and compared CWLP, LC diets, IF, and healthy eating. Based on the limited literature that is available, the exploratory hypotheses included: (a) the GHE group will display significantly higher mindfulness scores than other dieting groups, and (b) the GHE group will display significantly higher mindful eating scores than other dieting groups.

\section{PARTICIPANTS AND PROCEDURE}

\section{PARTICIPANTS}

A sample of 312 individuals residing in the district of West Midlands of the United Kingdom who were currently dieting took part in this study. Ninety-seven
Dieting reinforcing mindfulness and mindful eating 
participants were omitted due to not fully completing the questionnaire or being on diets that were too low in number for inclusion in the analysis. The sample $(N=215)$ was significantly made up of $60.93 \%$ female and $38.14 \%$ male, with a mean age of $36(S D=13.26)$. Using $\mathrm{G}^{*}$ Power, and aiming for a medium effect size at Power $=.8$, and $\alpha=.05$ indicated for four groups a total of 180 participants. No incentive or compensation was offered for participation. Table 1 displays the demographics of participants.

Rajkieren

Singh Manku, Helen Egan, Rebecca Keyte, Misba Hussain, Michail Mantzios

\section{INSTRUMENTS}

Participant information sheet. Participants were asked to report their age, gender, height, weight, ethnicity, and the diet they were currently following. Current dieting served as the independent variable, while the questionnaires served as the dependent variables of this research.

Five Facet Mindfulness Questionnaire (FFMQ; Baer, Smith, Hopkins, Krietemeyer, \& Toney, 2006). The FFMQ is a 39-item questionnaire measuring five main characteristics of mindfulness. Responses range from 1 (never or rarely true) to 5 (very often or always true). Sample items are 'I find it difficult to stay focused on what's happening in the present moment' (i.e. acting

Table 1

Demographics of participants

\begin{tabular}{lrr}
\hline Demographic variable & $n$ & $\%$ \\
\hline Gender & 82 & 38.14 \\
$\quad$ Male & 131 & 60.93 \\
$\quad$ Female & 2 & 0.93 \\
$\quad$ Prefer not to say & & \\
Ethnicity & 181 & 84.19 \\
$\quad$ White & 12 & 5.59 \\
$\quad$ Dual Heritage & 18 & 8.37 \\
$\quad$ Asian & 6 & 2.79 \\
$\quad$ South American & 2 & 0.93 \\
$\quad$ Black & 3 & 1.40 \\
$\quad$ Unknown & & \\
Diet type & 59 & 27.44 \\
General healthy eating & 47 & 21.86 \\
Intermittent fasting & 74 & 34.42 \\
Low carbohydrate diet & & 16.28 \\
Commercial weight loss & & \\
programme & & \\
\hline
\end{tabular}

with awareness) and 'usually when I have distressing thoughts or images I can just notice them without reacting' (i.e. non-reactive), and higher scores indicate higher levels of mindfulness. The five measured facets produced $\alpha$ values as follows: observing $(\alpha=.72)$, describing $(\alpha=.83)$, acting with awareness $(\alpha=.81)$, non-judging $(\alpha=.83)$ and non-reactivity $(\alpha=.89)$. The present study produced an overall Cronbach's $\alpha$ of .87 for the overall score.

Mindfulness Eating Scale (MES; Hulbert-Williams, Nicholls, Joy, \& Hulbert-Williams, 2014). The MES is a 28 -item scale, and is combined with five subscales, with responses ranging from 1 (never) to 4 (usually). Sample items include 'I wish I could control my eating more easily' (i.e. acceptance) and 'I notice flavours and textures when I'm eating my food' (i.e. awareness). Higher scores indicate higher levels of mindful eating. The five subscales produced the following $\alpha$ values: acceptance $(\alpha=.71)$, awareness $(\alpha=.75)$, non-reactivity $(\alpha=.67)$, routine $(\alpha=.71)$, distractibility $(\alpha=.70)$ and unstructured $(\alpha=.63)$. The present study produced an overall Cronbach's $\alpha$ of .75 for the total score.

\section{PROCEDURE}

The questionnaire was completed online and the study was advertised in fitness and professional fields. Those who wished to take part were asked to go to the study link, which led them through the participant information to the consent form, and after agreeing to take part, transferred participants to the questionnaires. After completing the questionnaires, they were directed to a debrief form. Ethical approval was granted through the University Research Ethics Committee and adhered to the strict guidelines of the British Psychological Society.

The analyses utilised a one-way ANOVA between the different diets on mindfulness and mindful eating.

\section{RESULTS}

The diet groups were compared on FFMQ and MES scale scores to determine differences in mindfulness and mindful eating. Descriptive statistics are displayed in Table 2 for the FFMQ and MES.

Both scales (FFMQ and MES) showed that IF consistently displayed higher scores. However, the ANOVA results suggested that the four diets were not significantly different for both the FFMQ scale $F(3,206)=0.18, p=.913$ and the MES scale $F(3,206)=1.30, p=.276$.

Further one-way ANOVAs were conducted exploring the sub-scales of the trait mindfulness (see Table 3) and mindful eating scales (see Table 4), indicating some significant findings. For trait mindful- 
ness, the LC group $(M=3.46, S D=1.03)$ obtained significantly lower scores in the 'observe' subscale in comparison to the CWLP group $(M=4.07$, $S D=0.69)$. For mindful eating, the CWLP group
$(M=4.07, S D=0.69)$ obtained significantly higher scores in the 'routine' subscale in comparison to the GHE group. The rest of the comparisons were not significantly different.

Table 2

Descriptive statistics of FFMQ and MES

\begin{tabular}{|c|c|c|c|c|c|c|}
\hline & & \multirow[t]{2}{*}{$M$} & \multirow[t]{2}{*}{$S D$} & \multirow[t]{2}{*}{$S E$} & \multicolumn{2}{|c|}{$\begin{array}{l}95 \% \text { confidence interval } \\
\text { for mean }\end{array}$} \\
\hline & & & & & Lower bound & Upper bound \\
\hline \multirow[t]{4}{*}{ FFMQ } & General healthy eating & 133.73 & 18.35 & 2.43 & 128.86 & 138.60 \\
\hline & IF & 135.93 & 29.22 & 4.26 & 127.35 & 144.51 \\
\hline & LC & 132.45 & 28.18 & 3.34 & 125.78 & 139.12 \\
\hline & CWLP & 133.91 & 24.31 & 4.10 & 125.56 & 142.26 \\
\hline \multirow[t]{4}{*}{ MES } & General healthy eating & 77.63 & 12.75 & 1.69 & 74.24 & 81.01 \\
\hline & IF & 80.68 & 13.18 & 1.92 & 76.81 & 84.55 \\
\hline & $\mathrm{LC}$ & 78.96 & 13.62 & 1.61 & 75.73 & 82.18 \\
\hline & CWLP & 75.22 & 11.57 & 1.95 & 71.24 & 79.19 \\
\hline
\end{tabular}

Note. IF - intermittent fasting, LC - low carbohydrate, CWLP - commercial weight loss programme.

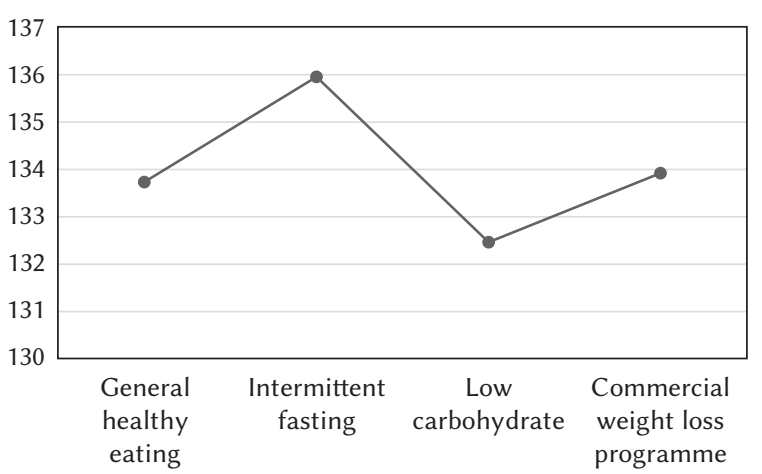

Figure 1. Mean Five-Facet Mindfulness Questionnaire (FFMQ) scores across the four diet groups.

Table 3

Trait mindfulness subscale analyses of variance across four dieting groups

\begin{tabular}{lccc}
\hline & $d f$ & $F$ & $p$ \\
\hline Observe & 3,210 & 0.32 & .812 \\
Describe & 3,210 & 4.26 & .006 \\
Awareness & 3,210 & 1.05 & .370 \\
Non-judge & 3,210 & 0.32 & .815 \\
Non-react & 3,210 & 1.16 & .325 \\
\hline
\end{tabular}

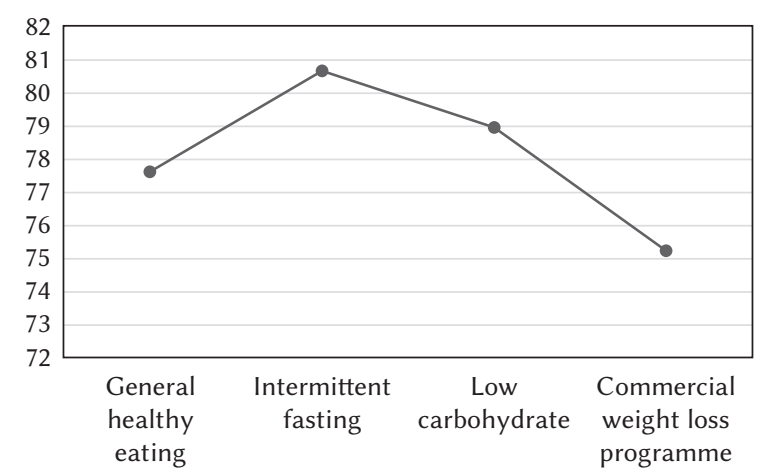

Figure 2. Mean Mindfulness Eating Scale (MES) scores across the four diet groups.

Table 4

Mindful eating subscale analyses of variance across four dieting groups

\begin{tabular}{lccc}
\hline & $d f$ & $F$ & $p$ \\
\hline Acceptance & 4,210 & 1.63 & .183 \\
Awareness & 4,210 & 0.60 & .623 \\
Non-reaction & 4,210 & 2.29 & .079 \\
Routine & 4,210 & 3.23 & .023 \\
Distracted Eating & 4,210 & 1.13 & .338 \\
Unstructured Eating & 4,210 & 1.55 & .202 \\
\hline
\end{tabular}

Dieting reinforcing mindfulness and mindful eating 


\section{DISCUSSION}

The overall aim was to explore popular diets and potential differences between them in mindfulness and mindful eating. The results indicated that there are statistically non-significant differences between the different diet types in mindfulness and mindful eating. Investigating mindfulness and mindful eating in more depth revealed some significant differences. For mindful eating, the subscale 'routine' scores were significantly higher for the CWLP group than for the GHE group. For trait mindfulness, the subscale 'describe' scores were higher for CWLP than for LC dieting. The results do not agree with previous suggestions in the mindfulness and mindful eating literature, and were not strong enough in indicating statistical significance of IF as suggested in the introduction. The results may be precursors for future research, especially when we attempt to explain the results.

IF appears to support mindful eating more than other diets, but in the present research this was not statistically adequate to expand the discussion to a greater extent. The results might have reached statistical significance with larger sample sizes, but it may be the case that there are other elements to explore simultaneously. For example, depriving oneself of food for several hours may mean that the next meal is approached impulsively, while impulsivity itself has been linked to obesity (Mobbs, Crepin, Thiery, Golay, \& van der Linden, 2010), which may form another method of relating to food. Future research needs to explore mindfulness and mindful eating in different diets, and specifically for IF, by incorporating an impulsivity scale to control for potential covariance. Another method could be to invite different dieters to participate in experimental research, and explore the potential of diets reinforcing or priming mindful eating principles. Closely aligned are the results for CWLP. Although significant, the primary question is whether the mindful eating subscale of routine and the trait mindfulness subscale of describe are elements that satisfactorily describe mindful eating and mindfulness. Readymade meals and point systems draw people away from active decision making and active engagement with food, which reinforces a mindless routine that is consistent with the results of this study, but is far from mindful eating. There are certainly different perceptions of dieting food (Sobal \& Cassidy, 1987), and further research needs to be conducted on dieting foods and the mindful and mindless properties of consuming those foods. Similarly, the way people have been taught to diet relates to being judgmental and critical of one's choices and can lead to very negative feelings about dieting (Egan \& Mantzios, 2018). Therefore, there may be some value as to how people relate to diet foods and palatable foods (Mantzios \& Egan, 2018), and potential associations and differences be- tween them, which could define the mindless and mindful relationships people have with food.

Another aspect that was briefly mentioned in the introduction was the occurrence of focusing on the future and judgment reinforcing the aim of dieting. Regardless of the diet, the potential focus on longterm goals may go against the principles of mindfulness and mindful eating, and the overarching aim to remain present and meal-focused. The diet at times may be very different from usual restrictive eating, where people exclude carbohydrates, eating readyprepared diet meals, focusing on 'points', the value of which may be prominently displayed on the packaging, all of which may change the dynamics of consumption and mindful consumption of food. It is possible that in an attempt to stick with the diet, people try not to think about what they are eating (or not eating), particularly as dieting is perceived as something that is undesirable and self-defeating (Mantzios \& Egan, 2018; Egan \& Mantzios, 2018).

A few limitations need to be considered. As mentioned previously, a larger sample could have highlighted the differences between some groups in this research. Another limitation is the limited information about dieting behaviours that was acquired from participants. Having more detailed information regarding how active current dieting behaviour is, including a history of dieting attempts and different diets used, as well as noting attempts to follow mindful eating principles in current and/or past dieting attempts, would have enabled a more tightly controlled investigation.

Overall, despite the significant and non-significant findings, this research has opened up another way of exploring research on mindfulness and eating. For patients in weight management, and for the general public who are overweight and obese, mixed messages about mindful eating reduce the possibility of achieving and maintaining optimal weight. In terms of applied research and practice, and the ability to investigate and redevelop diets that are themselves reinforcing, mindful eating may be a novel form of priming or nudging that is easy and effortless for people who are aiming to regulate their weight. Assimilating and developing the best methods that align with mindfulness and mindful eating principles may form another method of enhancing the efficiency and acceptability of mindfulness practices in the field of obesity and weight regulation.

\section{References}

Ahern, A. L., Olson, A. D., Aston, L. M., \& Jebb, S. A. (2011). Weight Watchers on prescription: an observational study of weight change among adults referred to Weight Watchers by the NHS. BMC Public Health, 11, 434. https://doi.org/10.1186/14712458-11-434 
Albers, S. (2003). Eating mindfully. Oakland, CA: New Harbinger Publications.

Alberts, H., Mulkens, S., Smeets, M., \& Thewissen, R. (2010). Coping with food cravings. Investigating the potential of a mindfulness-based intervention. Appetite, 55, 160-163. https://doi.org/10.1016/j.appet.2010.05.044

Baer, R. A., Smith, G. T., Hopkins, J., Krietemeyer, J., \& Toney, L. (2006). Using self-report assessment methods to explore facets of mindfulness. Assessment, 13, 27-45. https://doi.org/10.1177/1073191105283504

Bravata, D. M., Sanders, L., Huang, J., Krumholz, H. M., Olkin, I., Gardner, C. D., \& Bravata, D. M. (2003). Efficacy and safety of low-carbohydrate diets: a systematic review. Journal of American Medical Association, 289, 1837-1850. https://doi.org/10.1001/ jama.289.14.1837

Brownell, K., \& Rodin, J. (1994). The dieting maelstrom: Is it possible and advisable to lose weight? American Psychologist, 49, 781-791. https://doi. org/10.1037//0003-066x.49.9.781

Bruinsma, K. A., \& Taren, D. L. (2000). Dieting, essential fatty acid intake, and depression. Nutrition Reviews, 58, 98-108. https://doi.org/10.1111/j.1753-4887.2000. tb07539.x

Dalen, J., Smith, B. W., Shelley, B. M., Sloan, A. L., Leahigh, L., \& Begay, D. (2010). Pilot study: mindful eating and living (MEAL): weight, eating behaviour, and psychological outcomes associated with a mindfulness-based intervention for people with obesity. Complementary Therapies in Medicine, 18, 260-264. https://doi.org/10.1016/j.ctim.2010.09.008.

Dixon, K. J., Shcherba, S., \& Kipping, R. R. (2012). Weight loss from three commercial providers of NHS primary care slimming on referral in North Somerset: service evaluation. Journal of Public Health, 34, 555561. https://doi.org/10.1093/pubmed/fds034

Dutt, S., Keyte, R., Egan, H., Hussain, M., \& Mantzios, M. (2018). Healthy and unhealthy eating amongst stressed students: considering the influence of mindfulness on eating choices and consumption. Health Psychology Report, 7, 1-7. https:// doi.org/10.5114/hpr.2019.77913

Egan, H., \& Mantzios, M. (2018). A qualitative exploration of self-kindness and "treating oneself" in contexts of eating, weight regulation and other health behaviors: implications for mindfulnessbased eating programs. Frontiers in Psychology, 9, 880. https://doi.org/10.3389/fpsyg.2018.00880

Foxcroft, L. (2012). Our preoccupation with dieting has become a national neurosis. The Guardian. Retrieved from www.theguardian.com/commentisfree/2012/jan/01/preoccupation-diet-industrynational-neurosis

Germov, J., \& Williams, L. (1996). The epidemic of dieting women: the need for a sociological approach to food and nutrition. Appetite, 27, 97-108. https:// doi.org/10.1006/appe.1996.0038
Gilbert, D., \& Waltz, J. (2010). Mindfulness and health behaviours. Mindfulness, 1, 227-234. https://doi. org/10.1007/s12671-010-0032-3

Gu, J., Strauss, C., Bond, R., \& Cavanagh, K. (2015). How do mindfulness-based cognitive therapy and mindfulness-based stress reduction improve mental health and wellbeing? A systematic review and meta-analysis of mediation studies. Clinical Psychology Review, 37, 1-12. https://doi.org/10.1016/j. cpr.2015.01.006

Harvie, M. N., Pegington, M., Mattson, M. P., Frystyk, J., Dillon, B., Evans, G., Cuzick, J., Jebb, S. A., Martin, B., Cutler, R. G., Maudsley, S., Carlson, O. D., Egan, J. M., Flyvbjerg, A., \& Howell, A. (2011). The effects of intermittent or continuous energy restriction on weight loss and metabolic disease risk markers: a randomized trial in young overweight women. International Journal of Obesity, 35, 714-727. https://doi.org/10.1038/ijo.2010.171

Hendrickson, K. L., \& Rasmussen, E. B. (2017). Mindful eating reduces impulsive food choice in adolescents and adults. Health Psychology, 36, 226235. https://doi.org/10.1037/hea0000440

Heshka, S., Anderson, J. W., Atkinson, R. L., Greenway, F. L., Hill, J. O., Phinney, S. D., Kolotkin, R. L., Miller-Kovach, K., \& Pi-Sunyer, F. X. (2003). Weight loss with self-help compared with a structured commercial program: a randomized trial. Journal of American Medical Association, 289, 1792-1798. https://doi.org/10.1001/jama.289.14.1792

Hong, P., Lishner, D. A., \& Han, K. H. (2014). Mindfulness and eating: an experiment examining the effect of mindful raisin eating on the enjoyment of sampled food. Mindfulness, 5, 80-87. https://doi. org/10.1007/s12671-012-0154-x

Hulbert-Williams, L., Nicholls, W., Joy, J., \& HulbertWilliams, N. (2014). Initial validation of the mindful eating scale. Mindfulness, 5, 719-729. https:// doi.org/10.1007/s12671-013-0227-5

Hussein, M., Egan, H., \& Mantzios, M. (2017). Mindful construal diaries: a less anxious, more mindful, and more self-compassionate method of eating. Sage Open, 1-5. https://doi.org/10.1177/2158244017704685

Kabat-Zinn, J. (1990). Full catastrophe living. New York, NY: Delta Trade Paperbacks.

Kabat-Zinn, J. (2005). Coming to our senses: healing ourselves and the world through mindfulness. New York: Hyperion.

Kristeller, J. L., \& Wolever, R. Q. (2010). Mindfulnessbased eating awareness training for treating binge eating disorder: the conceptual foundation. Eating Disorders, 19, 49-61. https://doi.org/10.1080/10640 266.2011.533605

Last, A. R., \& Wilson, S. A. (2006). Low-carbohydrate diets. American Family Physician, 73, 1951-1958.

Lillis, J., Hayes, S., Bunting, K., \& Masuda, A. (2009). Teaching acceptance and mindfulness to improve the lives of the obese: a preliminary test of a theo-
Dieting reinforcing mindfulness and mindful eating 
retical model. Annals of Behavioral Medicine, 37, 58-69. https://doi.org/10.1007/s12160-009-9083-x

Mantzios, M., \& Egan, H. (2018). An exploratory examination of mindfulness, self-compassion, and mindful eating in relation to motivations to eat palatable foods and BMI. Health Psychology Report, 6, 207-2015. https://doi.org/10.5114/hpr.2018.73052

Mantzios, M., Egan, H., Bahia, H., Hussain, M., \& Keyte, R. (2018). How does grazing relate to body mass index, self-compassion, mindfulness and

Rajkieren

Singh Manku, Helen Egan, Rebecca Keyte, Misba Hussain, Michail Mantzios mindful eating in a student population? Health Psychology Open, 5, 1-7. https://doi.org/10.1177/ 2055102918762701

Mantzios, M., Egan, H., Hussain, M., Keyte, R., \& Bahia, H. (2018). Mindfulness, self-compassion, and mindful eating in relation to fat and sugar consumption: an exploratory investigation. Eating and Weight Disorders - Studies on Anorexia, Bulimia and Obesity, 23, 833-840. https://doi.org/1007/s40519018-0548-4

Mantzios, M., \& Giannou, K. (2014). Group vs. single mindfulness meditation: exploring avoidance, impulsivity, and weight management in two separate mindfulness meditation settings. Applied Psychology: Health and Well-Being, 6, 173-191. https://doi.org/10.1111/aphw.12023

Mantzios, M., \& Wilson, J. (2014a). Exploring mindfulness and mindfulness with self-compassioncentered interventions to assist weight loss: theoretical considerations and preliminary results of a randomized pilot study. Mindfulness, 6, 824-835. https://doi.org/10.1007/s12671-014-0325-z

Mantzios, M., \& Wilson, J. C. (2014b). Making concrete construals mindful: a novel approach for developing mindfulness and self-compassion to assist weight loss. Psychology \& Health, 29, 422-441. https://doi.org/10.1080/08870446.2013.863883

Mantzios, M., \& Wilson, J. C. (2015a). Mindfulness, eating behaviours, and obesity: a review and reflection on current findings. Current Obesity Reports, 4, 141-146. https://doi.org/10.1007/s13679014-0131-x

Mantzios, M., \& Wilson, J. C. (2015b). Exploring mindfulness and mindfulness with self-compassion-centered interventions to assist weight loss: theoretical considerations and preliminary results of a randomized pilot study. Mindfulness, 6, 824835. https://doi.org/10.1007/s12671-014-0325-z

Mantzios, M., Wilson, J. C., Linnell, M., \& Morris, P. (2015). The role of negative cognitions, intolerance of uncertainty, mindfulness, and self-compassion in weight regulation among male army recruits. Mindfulness, 6, 545-552. https://doi.org/10.1007/ s12671-014-0286-2

Mason, A. E., Epel, E. S., Kristeller, J., Moran, P. J., Dallman, M., Lustig, R. H., Acree, M., Bacchetti, P., Laraia, B. A., Hecht, F. M., \& Daubenmier, J. (2016). Effects of a mindfulness-based interven- tion on mindful eating, sweets consumption, and fasting glucose levels in obese adults: data from the SHINE randomized controlled trial. Journal of Behavioural Medicine, 39, 201-213. https://doi. org/10.1007/s10865-015-9692-8

Mintel (2014). Dieting in 2014? You're not alone 29 million Brits have tried to lose weight in the last year. Mintel.com. Retrieved from www.mintel. com/press-centre/social-and-lifestyle/dieting-in2014-you-are-not-alone

Mobbs, O., Crepin, C., Thiery, C., Golay, A., \& van der Linden, M. (2010). Obesity and the four facets of impulsivity. Patient, Education and Counseling, 79, 372-377. https://doi.org/10.1016/k.pec.2010.03.003

NHS (2016). Top diets review for 2016 - Live Well - NHS Choices. Retrieved from www.nhs.uk/ Livewell/loseweight/Pages/top-10-most-populardiets-review.aspx

NHS (2017). Fat: the facts - Live Well - NHS Choices. Retrieved from www.nhs.uk/Livewell/Goodfood/ Pages/Fat.aspx

O’Reilly, G. A., Cook, L., Spruijt-Metz, D., \& Black, D. S. (2014). Mindfulness-based interventions for obesity-related eating behaviours: a literature review. Obesity Reviews, 15, 453-461. https://doi. org/10.1111/obr.12156.

Peet, M. (2004). Diet, diabetes and schizophrenia: review and hypothesis. The British Journal of Psychiatry, 184, 102-105. https://doi.org/10.1192/bjp. 184.47.s 102

Schwartz, M. B., \& Brownell, K. D. (2004). Obesity and body image. Body Image, 1, 43-56. https://doi. org/10.1016/S1740-1445(03)00007-X

Sobal, J., \& Cassidy, C. M. (1987). Dieting foods: conceptualizations and explanations. Ecology of Food and Nutrition, 20, 89-96. https://doi.org/10.1080/03 670244.1987.9990990

Stinson, K. M. (2001). Women and dieting culture: inside a commercial weight loss group. New Brunswick, NJ: Rutgers University Press.

Tanskanen, A., Hibbeln, J. R., Tuomilehto, J., Uutela, A., Haukkala, A., Viinamäki, H., Lehtonen, J., \& Vartiainen, E. (2001). Fish consumption and depressive symptoms in the general population in Finland. Psychiatric Services, 52, 529-531. https://doi. org/10.1176/appi.ps.52.4.529

Tapper, K., Shaw, C., Ilsley, J., Hill, A. J., Bond, F. W., \& Moore, L. (2009). Exploratory randomised controlled trial of a mindfulness-based weight loss intervention for women. Appetite, 52, 396-404. https://doi.org/10.1016/j.appet.2008.11.012

Tomiyama, A. J., Mann, T., Vinas, D., Hunger, J. M., DeJager, J., \& Taylor, S. E. (2010). Low calorie dieting increases cortisol. Psychosomatic Medicine, 72, 357364. https://doi.org/10.1097/PSY.0b013e3181d9523c Tsai, A. G., \& Wadden, T. A. (2005). Systematic review: an evaluation of major commercial weight loss programs in the United States. Annals of Internal 
Medicine, 142, 56-66. https://doi.org/10.7326/00034819-142-1-200501040-00012

Wadden, T., Stunkard, A., \& Smoller, J. (1986). Dieting and depression: A methodological study. Journal of Consulting and Clinical Psychology, 54, 869-871. https://doi.org/10.1037//0022-006x.54.6.869

Warren, J. M., Smith, N., \& Ashwell, M. (2017). A structured literature review on the role of mindfulness, mindful eating and intuitive eating in changing eating behaviours: effectiveness and associated mechanisms. Nutrition Research Reviews, 30, 272283. https://doi.org/10.1017/S0954422417000154.

World Health Organization (2000). Obesity: preventing and managing the global epidemic (No. 894). World Health Organization. Retrieved from www. who.int/nutrition/publications/obesity/ $\mathrm{WHO}_{-}$ TRS_894/en/

Yancy, W. S., Olsen, M. K., Guyton, J. R., Bakst, R. P., \& Westman, E. C. (2004). A low-carbohydrate, ketogenic diet versus a low-fat diet to treat obesity and hyperlipidemia: a randomized, controlled trial. Annals of Internal Medicine, 140, 769-777. https://doi. org/10.7326/0003-4819-140-10-200405180-00006 